\title{
PEMODELAN PERKUATAN MENGGUNAKAN BAMBU UNTUK DAYA DUKUNG PONDASI DANGKAL PADA TANAH GAMBUT
}

\author{
Yulindasari Sutejo ${ }^{1)}$, Sutanto Muliawan'), Ratna Dewi ${ }^{3)}$, \\ Febrian Hadinata ${ }^{4)}$, Budi Ariawan", Reffanda Kurniawan Rustam? \\ 1,2,3,4,5) Jurusan Teknik Sipil FT UNSRI, J1. Raya Prabumulih -Km 32 Indralaya, Ogan Ilir, Sumsel \\ 6) Jurusan Teknik Sipil FT Universitas PGRI Palembang, Jl. A. Yani, Lr. Gotong Royong, 9/10 Ulu, Sumsel
}

\begin{abstract}
Some of the unfavorable characteristics of peat soil are low bearing capacity and high compressibility. The reinforcing material used in this research which functions the same as geogrid are bamboo materials (grids and woven). The bamboo material used aims to determine the carrying capacity and reduction of shallow foundations on peat soil before being reinforced and after being reinforced. Bamboo matting and rectangular patterned bamboo grids. Laboratory scale testing were used as the research methodology. The peat soil sampling location came from the area of Dusun III Banyu Urip, Banyuasin regency, South Sumatra province. The bamboo material is obtained from the Seberang Ulu area, Palembang City and sand is obtained from the sand depot in the Musi II area, Palembang City. The results of laboratory testing show that the addition of the number of reinforcement layers and the effective layer depth distance will give a greater bearing capacity ratio (BCR) value. The bearing capacity value of the shallow foundation before being reinforced on peat soil using Terzaghi's analysis is $45.232 \mathrm{kpa}$. Then, after testing the variation in the depth of the layer $d=0 b ; d=0.25 b$; and $d=0.5 b$ with the number of layers 1 layer, 2 layers and 3 layers obtained a variation which gives the highest bearing capacity value of layer depth variations $d=0.25 b$ with the number of layers of 3 layers. The bearing capacity value is $94 \mathrm{kpa}$ with a BCRvalue of 2.08 (percent increase of $107.96 \%$ ).
\end{abstract}

Key Words: bamboo, bearing capacity, peat soil, shallow foundation

\section{PENDAHULUAN}

Penurunan dan daya dukung menjadi masalah utama yang harus diperhatikan jika pembangunan dilakukan di atas tanah lunak. Pembangunan konstruksi pondasi merupakan suatu bagian yang tidak dapat dihilangkan. Pondasi merupakan salah satu struktur pendukung yang memiliki beberapa jenis, salah satunya adalah pondasi dangkal. Pondasi dangkal merupakan struktur yang paling banyak digunakan baik pada rumah tinggal maupun bangunan struktur lainnya. Pada perancangan pondasi hal yang paling dipertimbangkan adalah kondisi tanahnya.

Das (2010) mendefinisikan tanah gambut sebagai agregat agak berserat yang berasal dari serpihan mikroskopik dan makroskopik tumbuh-tumbuhan. Jika ditinjau dari segi warna, maka terlihat seperti hitam dan coklat. Tanah gambut bersifat kompresibel. Oleh karena itu, tanah gambut sulit untuk mendukung pondasi. Selain itu, parameter berat isi yang kecil pada tanah gambut menyebabkan beban daya dukungnya juga kecil. Sifat lain dari tanah gambut yang berbeda dari tanah yang lain yaitu sifat mengering tidak balik (irreversible drying) yang dapat menyebabkan tanah gambut cepat menyusut serta mengalami penurunan permukaan tanah.

Apabila terjadi perbedaan penurunan yang berlebih, dan untuk meningkatkan daya dukung, tanah gambut dapat diperbaiki dengan menambahkan material. Proses penurunan yang terjadi masih dalam batas toleransi, diharapkan dapat mengurangi kemungkinan kerusakan pada bangunan konstruksi yang dibangun di atasnya.

Penambahan material perkuatan menjadi salah satu metode perbaikan tanah gambut agar daya dukungnya bertambah. Supriyati dkk. (2015) menggunakan bahan kayu gelam sebagai material perkuatan menjadi cerucuk/tiang pancang rumah di atas tanah gambut. Pengunaan kayu gelam ini ini bertujuan untuk melestarikan hutan di area tanah gambut. Selain itu, penelitian dari Susanti dkk (2017) mendeskripsikan pengujian laboratorium sebelum dan sesudah preloading pada tanah gambut. Metode preolading dapat membantu percepatan proses pemampatan sehingga daya dukung tanah gambut meningkat. 
Pada penelitian ini, untuk mendapatkan material perkuatan yang tepat untuk tanah gambut, dilakukan penelitian mengenai perkuatan menggunakan material bambu. Pemilihan material bambu dilakukan dengan pertimbangan material tersebut mudah ditemukan dan dalam aspek biaya tidak terlalu mahal, sehingga tidak menyulitkan untuk lokasi pembangunan di daerah yang terpencil. Dari hasil penelitian ini, diharapkan dengan perkuatan material bambu, maka daya dukung tanah gambut sebagai tanah dasar dari pondasi dangkal akan meningkat.

\section{Tanah Gambut}

Pembangunan konstruksi jarang dilakukan di atas tanah gambut. Dalam serat-serat tanah gambut terdapat pori-pori mikro. Beberapa sifat tanah gambut yang bermasalah, seperti: tingkat homogenitas yang tidak merata, sistem pori ganda, berat isi tanah yang mendekati berat isi air. Hal ini dapat menimbulkan pemampatan yang relatif besar sehingga penurunan yang terjadi juga besar. Tanah gambut juga bersifat sangat lembek yang mengakibatkan tanah gambut mempunyai daya dukung (bearing capacity) yang rendah. Hasil penelitian dari Jelisic dkk. (1993) yaitu nilai parameter daya dukung tanah gambut lebih rendah dari pada tanah soft clay sehingga bisa mengakibatkan keruntuhan (bearing capacity failure).

\section{Pondasi Dangkal}

Pondasi dangkal merupakan salah satu konstruksi bangunan yang terletak paling bawah (Das, 2010). Fungsi dari pondasi dangkal yaitu mendistribusikan seluruh beban bangunan ke lapisan tanah yang berada relatif dekat dengan permukaan tanah. Pondasi yang memiliki kedalaman lebih kecil atau sama dengan dimensi lebar pondasi adalah pondasi dangkal. Apabila kondisi kedalaman pondasi mencapai $3 \mathrm{x}$ hingga $4 \mathrm{x}$ dari lebar pondasi maka masih dikategorikan sebagai pondasi dangkal.

Daya dukung tanah yang mendukung beban pondasi yang terletak di atas suatu konstruksi struktur dapat dianalisa kapasitas dukung tanah tersebut. Perlawanan tahanan geser tanah untuk menahan terjadinya penurunan karena adanya pembebanan merupakan pengertian dari kapasitas dukung tanah. Tahanan geser tanah ini bekerja disepanjang bidang-bidang gesernya.

Penelitian Kumar dkk (2003) menganalisa daya dukung perkuatan tanah dengan menggunakam metode rectangular footing. Metode analisis daya dukung tanah untuk menghitung intensitas tekanan yang terjadi dengan penurunan pada pondasi tanah yang diperkuat.
Yadu dkk. (2013) juga meneliti mengenai daya dukung pada tanah dasar lunak. Dalam penelitian ini, dilakukan pengujian apakah panjang lapisan geogrid berpengaruh terhadap rasio daya dukung sistem tanah dasar geogrid yang diperkuat timbunan granular. Hasil pengujian menunjukkan peningkatan daya dukung dan penurunan pondasi akibat penggunaan geogrid pada timbunan granular pada tanah dasar lunak.

1) Kapasitas daya dukung tanah Terzaghi

Daya dukung tanah untuk Analisa Terzaghi secara umum adalah:

$\mathrm{q}_{\mathrm{u}}=\mathrm{c} \mathrm{N} \mathrm{N}_{\mathrm{c}} \mathrm{S}_{\mathrm{c}}+\gamma \mathrm{D}_{\mathrm{f}} \mathrm{N}_{\mathrm{q}}+0,5 \gamma \mathrm{B} \mathrm{N}_{\gamma} \mathrm{S}_{\gamma}$

Bentuk pondasi bujur sangkar menggunakan Persamaan (2).

$\mathrm{q}_{\mathrm{u}}=1,3 \mathrm{c} \mathrm{N} \mathrm{N}_{\mathrm{c}}+\gamma \mathrm{D}_{\mathrm{f}} \mathrm{N}_{\mathrm{q}}+0,4 \gamma \mathrm{B} \mathrm{N}$

Bentuk pondasi lingkaran menggunakan Persamaan (3).

$\mathrm{q}_{\mathrm{u}}=1,3 \mathrm{c} \mathrm{N} \mathrm{N}_{\mathrm{c}}+\mathrm{P}_{\mathrm{o}} \mathrm{N}_{\mathrm{q}}+0,3 \gamma \mathrm{B} \mathrm{N}_{\gamma}$

Bentuk pondasi menerus menggunakan persamaan (4):

$\mathrm{q}_{\mathrm{u}}=\mathrm{c} \mathrm{N} \mathrm{N}_{\mathrm{c}}+\gamma \mathrm{D}_{\mathrm{f}} \mathrm{N}_{\mathrm{q}}+0,5 \gamma \mathrm{B} \mathrm{N}$

Keterangan:

$\mathrm{q}_{\mathrm{u}}\left(\mathrm{kN} / \mathrm{m}^{2}\right)=$ Daya dukung ultimit pondasi dangkal

$\mathrm{N}=$ Faktor kapasitas dukung tanah, nilainya dari parameter sudut gesek dalam $(\phi)$ tanah di bawah dasar pondasi dangkal

$\mathrm{L}(\mathrm{m}) \quad=$ Panjang pondasi dangkal

$\mathrm{B}(\mathrm{m})=$ Diameter/Lebar pondasi dangkal

$\mathrm{c}\left(\mathrm{kN} / \mathrm{m}^{2}\right)=$ Kohesi tanah

$\operatorname{Po}\left(\mathrm{kN} / \mathrm{m}^{2}\right)=$ Tekanan overbuden pada dasar pondasi dangkal

$\mathrm{D}_{\mathrm{f}}(\mathrm{m})=$ Kedalaman pondasi dangkal

$\gamma\left(\mathrm{kN} / \mathrm{m}^{3}\right)=$ Berat volume tanah

2) Kapasitas daya dukung Skempton

Persamaan daya dukung ultimit menurut Skempton adalah:

$\mathrm{q}_{\mathrm{u}}=\mathrm{c}_{\mathrm{u}} \mathrm{N}_{\mathrm{c}}+\mathrm{D} f .$.

Keterangan:

$\mathrm{q}_{\mathrm{u}}\left(\mathrm{kN} / \mathrm{m}^{2}\right)=$ Daya dukung ultimit pondasi dangkal

$\mathrm{N}_{\mathrm{c}} \quad=$ Faktor daya dukung Skempton

$\gamma\left(\mathrm{kN} / \mathrm{m}^{3}\right)=$ Berat volume tanah

$\mathrm{c}_{\mathrm{u}}\left(\mathrm{kN} / \mathrm{m}^{2}\right)=$ Kohesi tanah

$\mathrm{D}_{\mathrm{f}}(\mathrm{m}) \quad=$ kedalaman pondasi dangkal 
3) Kapasitas daya dukung tanah Meyerhof

Persamaan daya dukung ultimit tanah menurut Meyerhof adalah:

$q_{u}=S_{c} d_{c} i_{c} c N_{c}+S_{q} d_{q} i_{q} p_{o} N_{q}+S_{\gamma} d_{\gamma} i_{\gamma} 0,5 B^{\prime} \gamma N_{\gamma} \ldots(6)$

Keterangan:

$\mathrm{q}_{\mathrm{u}}\left(\mathrm{kN} / \mathrm{m}^{2}\right)=$ Daya dukung ultimit pondasi dangkal

$\mathrm{N}_{\mathrm{c}}, \mathrm{N}_{\mathrm{q}}, \mathrm{N}_{\gamma}=$ Faktor daya dukung pondasi dangkal

$\mathrm{i}_{\mathrm{c}}, \mathrm{i}_{\mathrm{q}}, \mathrm{i}_{\gamma} \quad=$ Faktor kemiringan beban

$\mathrm{S}_{\mathrm{c}}, \mathrm{S}_{\mathrm{q}}, \mathrm{S}_{\gamma} \quad=$ Faktor bentuk

$\mathrm{d}_{\mathrm{c}}, \mathrm{d}_{\mathrm{q}}, \mathrm{d}_{\gamma}=$ Faktor kedalaman

$\mathrm{c}\left(\mathrm{kN} / \mathrm{m}^{2}\right)=$ Kohesi tanah

$\mathrm{B}^{\prime}(\mathrm{B}-2 \mathrm{e})=$ Lebar pondasi efektif

Nilai perbandingan antara daya dukung ultimit tanah pondasi yang diberi perkuatan $\left(\mathrm{q}_{\mathrm{r}}\right)$ dengan daya dukung ultimit tanah pondasi yang tidak diberi perkuatan $\left(\mathrm{q}_{\mathrm{o}}\right)$ merupakan nilai Bearing Capacity Ratio (BCR). Nilai BCR ini diperoleh apabila analisis dimensionless telah selesai. Umumnya nilai BCR dinyatakan dalam persen (\%). Nilai Bearing Capacity Ratio (BCR) akan digunakan untuk mengetahui apakah daya tanah yang telah diberi perkuatan mengalami peningkatan. Berikut ini persamaan untuk mendapatkan nilai BCR:

$\mathrm{BCR}=\frac{q_{r}}{q_{0}}$

Keterangan:

$\mathrm{qr}=$ Nilai daya dukung ultimit tanah pondasi yang diberi perkuatan

qo $=$ Nilai daya dukung ultimit tanah pondasi yang tidak diberi perkuatan

Salah satu material bahan konstruksi yaitu dari bahan kayu (Anonim, 1999). Properti kayu dan produk berbasis kayu menjadi perhatian khusus untuk arsitek dan insinyur. Seperti, material kayu dapat dipakai untuk bangunan rumah dan menjadi kayu olahan (Green Building Material). Krisdianto dkk. (2006) menyatakan bahwa bambu adalah salah satu bahan bangunan dari tumbuhan digunakan untuk tujuan konstruksi bangunan. Bambu berasal dari sejenis kayu berbentuk ruas-ruas dan pembuluh.

Di Indonesia, bambu menjadi salah satu jenis kayu yang sering dijumpai. Bambu sering digunakan untuk sebagai material konstruksi seperti pipa air, cerucuk untuk stabilisasi tanah, dan sebagai tiang. Jika ditinjau dari segi harga, maka harga bambu lebih murah apabila dibandingkan dengan jenis material kayu lainnya. Bambu memiliki keunggulan antara lain:

1) Bambu mudah ditanam dan tidak memerlukan pemeliharaan yang khusus.

2) Masa pertumbuhan bambu cepat.

3) Harganya murah dan mudah didapat.

\section{METODOLOGI PENELITIAN}

Metode pengujian laboratorium merupakan metode penelitian yang digunakan untuk mengetahui pemodelan perkuatan dengan bambu. Laboratorium yang dipakai untuk pengujian ini adalah Laboratorium Mekanika Tanah, Jurusan Teknik Sipil Fakultas Teknik, Universitas Sriwijaya, Inderalaya. Sampel tanah gambut untuk pengujian perkuatan dalam penelitian ini berasal dari Dusun III Banyu Urip Kecamatan Tanjung Lago Kabupaten Banyuasin. Hasil pengujian sifat fisik dan kimiawi dari sampel tanah gambut yang diambil dari penelitian terdahulu:Sutejo (2019). Penelitian ini menggunakan pemodelan pondasi dari bahan pelat besi. Ukuran dimensi pemodelan yaitu $15 \mathrm{~cm} \mathrm{x}$ $15 \mathrm{~cm} \times 2 \mathrm{~cm}$.

Selain itu, ukuran bak uji dari bahan besi las dan bahan triplek sebagai dindingnya yaitu $90 \mathrm{~cm}$ x 90 $\mathrm{cm} \times 100 \mathrm{~cm}$. Pemodelan perkuatan dengan material bambu menggunakan pola anyaman dan grid. Jenis bambu pada pemodelan ini adalah jenis bambu petung. Jenis bambu petung berasal dari Daerah Seberang Ulu Kota Palembang.

Usman (2014) melakukan peneltian pada tanah gambut dengan material bambu yang menggunakan kombinasi anyaman dan grid bambu dengan variasi jumlah lapisan dan lebar. Selain itu, beberapa penelitian lainnya seperti Dewi et.al. (2020), Nugroho (2011), Aazokhi (2014), dan Widianti (2012) juga menggunakan bahan material bambu sebagai material perkuatan tanah.

Penelitian ini, menggunakan pemodelan dilakukan dengan menggunakan variasi kedalaman lapisan $d=0 B ; d=0,25 B ; d=0,5 B$ dan variasi jumlah lapis perkuatan Pengujian dilakukan dengan memberikan besi beban yang diletakkan pada lengan beban kepada tanah kemudian penurunan pelat pondasi dicatat mengguakan LVDT.

Pada saat dilakukan pembebanan penurunan yang diizinkan tidak lebih dari $10 \%$ diameter pelat pondasi apabila itu terjadi maka pengujian dihentikan dan dilakukan pengujian pada variasi selanjutnya. Pembebanan dilakukan mengunakan besi beban dengan static load tanpa adanya faktor kejut, fluktuasi atau eksentrisitas. Pada saat pembebanan perlu diperhatikan waktu interval pembebanan, yang dimaksud disini adalah setelah aplikasi dari penambahan beban waktu interval yang diizinkan tidak kurang dari 15 menit. Pemodelan pengujian perkuatan denan bamboo dapat dilihat pada Gambar 1. 


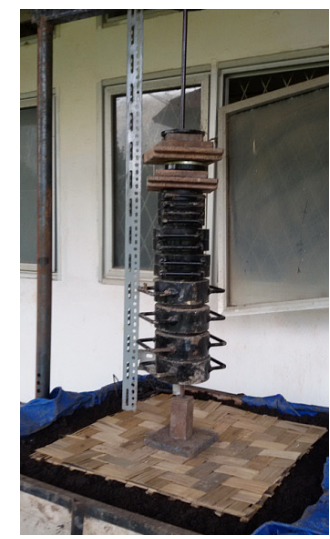

Gambar 1. Model Pengujian dengan 1 Lapis Perkuatan

Nilai penurunan dan beban didapatkan dari hasil pengujian di atas. Kemudian berdasarkan hubungan antara kedua nilai tersebut maka akan diperoleh nilai perkuatan daya dukung ultimit $\left(\mathrm{q}_{\mathrm{u}}\right)$ tanah gambut dari hasil pengujian di masing-masing variasi. Hasil pengujian dengan perkuatan dibandingkan dengan hasil pengujian tanpa perkuatan sehingga didapat parameter nilai Bearing Capacity Ratio (BCR). Dari hasil ratio nilai BCR ini, dapat diketahui apakah pemodelan perkuatan tanah gambut dengan material bambu dapat meningkatkan daya dukung tanah tersebut.

\section{HASIL DAN PEMBAHASAN}

\subsection{Daya Dukung Tanah Gambut Tanpa Perkuatan}

Nilai daya dukung tanah tanpa perkuatan didapat dari hasil analisa perhitungan dengan metode analisa Terzaghi. Data parameter tanah gambut yaitu: c' $=$ $0,0467 \mathrm{~kg} / \mathrm{cm}^{2} ; \varnothing=7,65^{\circ} ; \mathrm{N}^{\prime}{ }_{\mathrm{c}}=5,6536 ; \mathrm{N}_{\mathrm{q}}{ }=$ 2,$1612 ; \mathrm{N}^{\prime}{ }_{\gamma}=0,336 ; \gamma=1,735.10^{-3} \mathrm{Kg} / \mathrm{cm}^{3} ; \gamma=$ $1,735 \times 10^{-3} \mathrm{Kg} / \mathrm{cm}^{3}$

$$
\begin{aligned}
& \text { Qultimit }=1,3 \mathrm{c}^{\prime} \mathrm{N}_{\mathrm{c}}+\mathrm{P}_{\mathrm{o}} \mathrm{N}_{\mathrm{q}}+0,4 \gamma \mathrm{B} \mathrm{N}_{\gamma} \\
& =0,45232 \mathrm{Kg} / \mathrm{cm}^{2} \\
& =45,232 \mathrm{kPa}
\end{aligned}
$$

\subsection{Daya Dukung Tanah Gambut Dengan Perkuatan}

Hasil dari pengujian pembebanan dengan variasi kedalaman lapisan $\mathrm{d}=0 \mathrm{~B} ; \mathrm{d}=0,25 \mathrm{~B} ; \mathrm{d}=0,5 \mathrm{~B}$ dan variasi jumlah lapisan perkuatan 1 lapis, 2 lapis, dan 3 lapis didapatkan nilai daya dukung terbesar adalah pada variasi kedalaman lapisan $\mathrm{d}=0,25 \mathrm{~B}$ dengan jumlah lapisan 3 lapis yaitu sebesar $94 \mathrm{kPa}$.

Rekapitulasi nilai daya dukung ultimit tanah gambut dengan perkuatan ditunjukkan pada Tabel 1. Grafik 2 menjelaskan grafik korelasi antara penurunan beban menggunakan 3 lapis perkuatan dengan kedalaman $d=0,25 \mathrm{~b}$. Berdasarkan Tabel 1 dan Gambar 2 dapat dilihat bahwa kedalaman dan jumlah lapisan perkuatan mempengaruhi hasil daya dukung tanah gambut. Kondisi pemodelan perkuatan dengan kedalaman lapisan (d) yang semakin efektif dan jumlah lapisan perkuatan yang banyak menghasilkan nilai daya dukung tanah

\begin{tabular}{|c|c|c|c|c|c|c|}
\hline $\begin{array}{c}\text { Lebar } \\
\text { Perkua } \\
\quad \tan \end{array}$ & $\begin{array}{l}\text { Kedalam } \\
\text { an }\end{array}$ & \begin{tabular}{|c} 
Jumlah \\
Lapis \\
Perkuat \\
an
\end{tabular} & $\begin{array}{l}\text { qultimit } \\
(\mathrm{kPa})\end{array}$ & $\begin{array}{c}\mathrm{q}_{\text {izin }} \\
(\mathrm{kPa})\end{array}$ & $\begin{array}{c}\text { BCR } \\
(\mathrm{qu} / \mathrm{qo})\end{array}$ & $\begin{array}{c}\text { Persen } \\
\text { Peningkatan } \\
\text { BCR } \\
(\%)\end{array}$ \\
\hline \multirow{10}{*}{$\begin{array}{l}\text { Varia } \\
\text { si lebar } \\
\text { per } \\
\text { kuatan } \\
(60 \mathrm{~cm} \\
\text { x } 60 \\
\mathrm{~cm})\end{array}$} & $\begin{array}{c}\text { Tanpa } \\
\text { Perkuatan }\end{array}$ & - & - & 45,23 & 1,00 & - \\
\hline & \multirow{3}{*}{$\begin{array}{c}d=0 \\
B\end{array}$} & 1 & 60,67 & - & 1,35 & 34,81 \\
\hline & & 2 & 65,11 & - & 1,45 & 44,69 \\
\hline & & 3 & 70,44 & - & 1,57 & 56,54 \\
\hline & \multirow{3}{*}{$\begin{array}{c}d= \\
0,25 B\end{array}$} & 1 & 71,78 & - & 1,59 & 58,80 \\
\hline & & 2 & 85,11 & - & 1,88 & 88,30 \\
\hline & & 3 & 94,00 & - & 2,08 & 107,96 \\
\hline & \multirow{3}{*}{$\mathrm{d}=0,5 \mathrm{~B}$} & 1 & 65,56 & - & 1,45 & 45,03 \\
\hline & & 2 & 79,78 & - & 1,77 & 76,50 \\
\hline & & 3 & 88,67 & - & 1,96 & 96,02 \\
\hline
\end{tabular}
gambut yang besar pula.

Tabel 1. Daya Dukung Ultimit Tanah dengan Perkuatan

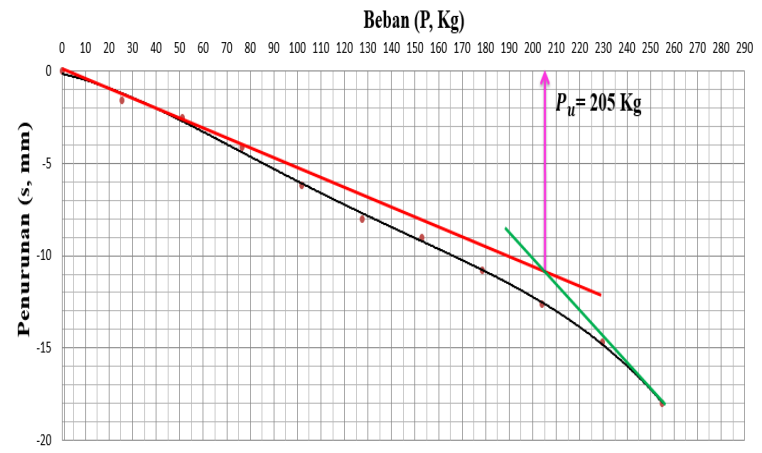

Gambar 2. Grafik korelasi penurunan beban dengan kedalaman

\section{Nilai BCR (Bearing Capacity Rasio)}

Rasio daya dukung BCR (Bearing Capacity Rasio) adalah nilai rasio perbandingan antara nilai daya dukung tanah yang diberi perkuatan dengan material bambu dengan nilai daya dukung tanah tanpa perkuatan. Pada penelitian ini, nilai rasio inilah yang digunakan sebagai tolak ukur keefektifan beberapa variasi yang dipakai dalam perkuatan.

Hasil pengujian dari material perkuatan dengan bahan bambu dengan pola anyaman dan grid diperoleh nilai BCR yang meningkat. Semakin besar dimensi perkuatan dan jumlah lapis perkuatan yang banyak, maka semakin besar pula nilai BCR (Bearing Capacity Rasio). Tabel 2 memperlihatkan hasil perhitungan nilai BCR Bearing Capacity Rasio). Nilai BCR dengan variasi kedalaman lapisan dan variasi jumlah lapis perkuatan dijelaskan pada Gambar 2 dan Gambar 3. 
Tabel 2. Rekapitulasi Perhitungan BCR dan Persen Peningkatan BCR

\begin{tabular}{|c|c|c|c|}
\hline \multicolumn{2}{|c|}{ Variasi } & \multirow{2}{*}{$\begin{array}{c}\text { Jumlah } \\
\text { Lapis }\end{array}$} & \multirow[b]{2}{*}{ qultimit (kPa) } \\
\hline Perkuatan & Kedalaman & & \\
\hline \multirow{10}{*}{$\begin{array}{c}\text { Variasi lebar } \\
\text { perkuatan } \\
(60 \mathrm{~cm} \times 60 \\
\mathrm{cm})\end{array}$} & $\begin{array}{c}\text { Tanpa } \\
\text { Perkuatan }\end{array}$ & - & 45,23 \\
\hline & \multirow{3}{*}{$d=0 B$} & 1 & 60,67 \\
\hline & & 2 & 65,11 \\
\hline & & 3 & 70,44 \\
\hline & \multirow{3}{*}{$\mathrm{d}=\mathbf{0 , 2 5} \mathrm{B}$} & 1 & 71,78 \\
\hline & & 2 & 85,11 \\
\hline & & 3 & 94,00 \\
\hline & \multirow{3}{*}{$\mathrm{d}=0,5 \mathrm{~B}$} & 1 & 65,56 \\
\hline & & 2 & 79,78 \\
\hline & & 3 & 88,67 \\
\hline
\end{tabular}

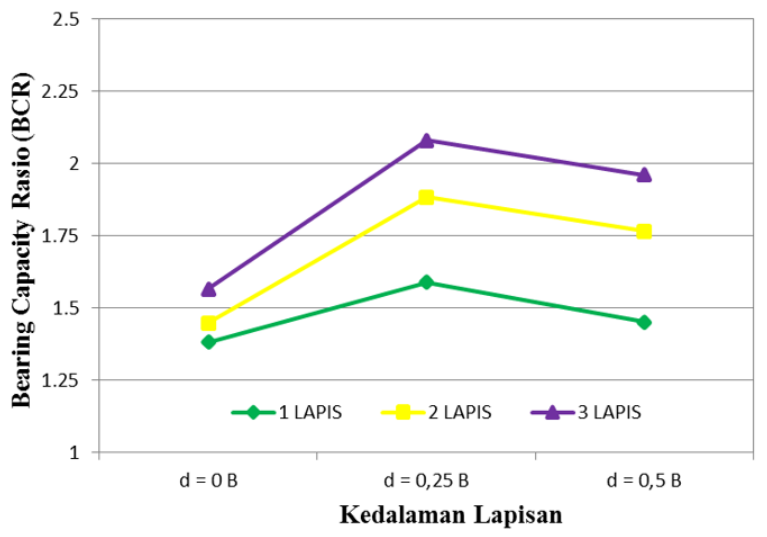

Gambar 3. Grafik Kenaikan Nilai BCR dengan Variasi Kedalaman Lapisan

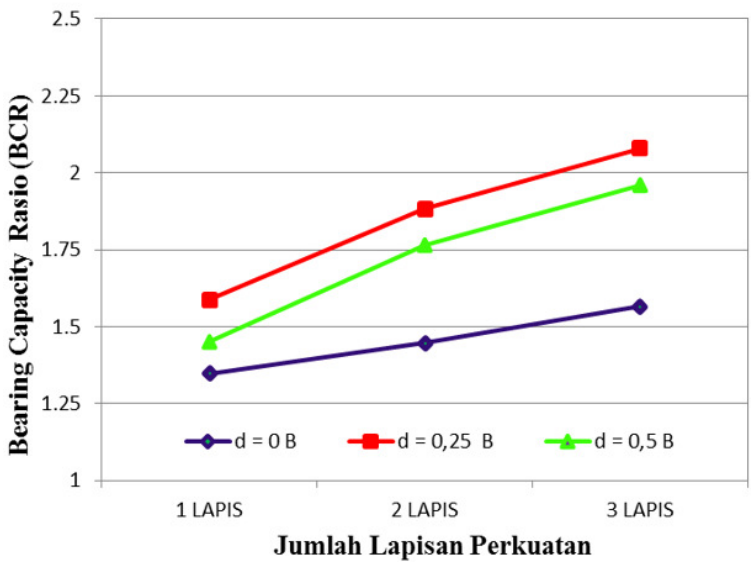

Gambar 4. Grafik Kenaikan Nilai BCR dengan Variasi Jumlah Lapis Perkuatan

Berdasarkan nilai bearing capacity rasio (BCR) yang diperoleh dari dari Tabel 2 dan Gambar 3, dapat disimpulkan bahwa nilai BCR yang paling besar adalah pada variasi kedalaman lapisan $\mathrm{d}=$ 0,25 B dengan variasi jumlah lapisan 3 lapis. Pada variasi kedalaman (d), didapatkan hasil bahwa nilai kedalaman (d) yang paling efektif ialah pada kedalaman $\mathrm{d}=0,25 \mathrm{~B}$. Kedalaman lapisan (d) yang paling optimal diperoleh pada kedalaman $d=0,25$ B. Hal ini dikarenakan keruntuhan pondasi pada tanah dengan perkuatan terdapat sudut penyebaran tegangan. Sudut penyebaran pada kedalaman $d=$ 0,25 memberikan peran lapis perkuatan yang paling efektif.

Kondisi perkuatan yang lebih besar dapat menanggung tegangan yang terjadi pada pondasi. Sudut penyebaran tegangan yang terlalu kecil dan terlalu besar, akan memberikan peran perkuatan yang kurang efektif dikarenakan semakin jauh kedalaman (d) akan mengurangi peran dari perkuatan itu sendiri, dan tegangan yang ditanggung perkuatan akan semakin kecil. Dari Gambar 3 di atas, dapat disimpulkan bahwa nilai bearing capacity rasio (BCR) akan selalu meningkat seiring dengan bertambahnya jumlah lapisan.

Hal ini dikarenakan pemodelan perkuatan di dalam tanah memerlukan kondisi gabungan yang harus diatur dengan perhitungan analisa yang baik. Sehingga dengan kondisi tersebut, tentunya perilaku yang dihasilkan juga kan menjadi lebih baik. Sifat tanah lunak umumnya yaitu mempunyai daya tarik yang kurang baik dan daya tekan yang cukup baik. Pemodelan perkuatan yang dilakukan pada penelitian ini memperbaiki sifat daya darik dari tanah gambut. Semakin banyak jumlah lapis perkuatan yang digunakan, maka pada saat terjadi keruntuhan tanah akan semakin cepat tertahan oleh banyaknya lapis perkuatan yang dipasang dibawahnya.

\section{KESIMPULAN}

Adapun kesimpulan yang dapat diperoleh dari analisa data dan pembahasan adalah nilai daya dukung pondasi dangkal pada tanah gambut dengan menggunakan analisa Terzaghi sebesar 45,232 kPa, analisa Meyerhof, sebesar 49,73 $\mathrm{kPa}$, dan analisa Skempton sebesar 45,5 kPa. Nilai daya dukung (qult) maksimal pondasi dangkal pada tanah gambut setelah diberi perkuatan grid dan anyaman bambu berada pada rasio kedalaman $\mathrm{d}=0,25 \mathrm{~B}$ dengan 3 lapis perkuatan. Nilai daya dukungnya sebesar 94 $\mathrm{kPa}$ atau 107,96\%. Hasil penelitian ini menunjukkan bahwa perkuatan grid bambu dan anyaman bambu dapat meningkatkan nilai daya dukung ( $q_{\text {ult }}$ ) pada tanah gambut. Lebar kedalaman pondasi yang semakin efektif dan jumlah lapis perkuatan yang semakin banyak maka nilai rasio daya dukung BCR (Bearing Capacity Rasio) tanah gambut semakin meningkat . 


\section{UCAPAN TERIMA KASIH}

Penelitian ini merupakan bagian dari Penelitian Unggulan Kompetitif Universitas Sriwijaya Tahun 2020 .

\section{REFERENSI}

Aazokhi W. (2014). Bamboo Reinforcement in Shallow Foundation on the Peat Soil, Journal of Civil Engineering Research, 4(3A), 96-102.

Anonim, (1999). Wood Handbook-Wood as an Engineering Material, USA: Forest Products Society.

Das, B. M. (2010). Principles of Geotechnical Engineering, 7th Edition. Stamford, USA: Cengage Learning.

Dewi, R., Hastuti, Y., Sutejo, Y., Iqbal, M., M., \& Arfan, M. (2020). Peat Soil Improvement Method Using Woven Bamboo and Cerucuk. International Journal on Advanced Science, Engineering and Information Technology, 10(4), 1617-1623.

Jelisic, N. \& Leppanen, M. (1993). Mass Stabilization Tanah Gambut pada Konstruksi Jalan Raya dan Rel Kereta Api.

Kumar, A. \& Saran, S., (2003). Bearing Capacity of Rectangular Footing on Reinforced Soil. Geotechnical and Geological Engineering, 21: 201-224

Krisdianto, G. S. \& Ismanto, A. 2006. Sari Hasil Penelitian Bambu, Jakarta: Departemen Kehutanan.
Nugroho, S. A. (2011). Studi Daya Dukung Pondasi Dangkal Pada Tanah Gambut Dengan Kombinasi Geotekstil Dan Grid Bambu. Jurnal Teknik Sipil: Jurnal Teoritis dan Terapan Bidang Rekayasa Sipil, 18(1), 31-40.

Sutejo, Y., Saggaff, A., Rahayu, W., \& Hanafiah. (2019). Laboratory Investigation of The Suction of Peat Soil in Drying and Wetting Process. International Journal of Scientific \& Technology Research, 8(12), 73-79.

Susanti, R, Maulana, \& Waruwu, A. (2017). Bearing Capacity Improvement of Peat Soil by Preloading. ARPN Journal of Engineering and Applied Science, 12(1), 121-124.

Supriyati, W., Prayitno, T. Sumardi S., \& Marsoem, S.N. (2015). Kearifan Lokal Penggunaan Kayu Gelam dalam Tanah Rawa Gambut di Kalimantan Tengah. Manusia dan Lingkungan, 22(1), 94-99.

Usman, A. (2014). Studi Daya Dukung Pondasi Dangkal Pada Tanah Gambut Menggunakan Kombinasi Perkuatan Anyaman Bambu Dan Grid Bambu Dengan Variasi Lebar Dan Jumlah Lapisan Perkuatan. Jurnal Teknik Sipil dan Lingkungan, Teknik Sipil Universitas Sriwijaya, Palembang.

Widianti A. (2012). Pengaruh Jumlah Lapisan Dan Spasi Perkuatan Geosintetik Terhadap Kuat Dukung Dan Penurunan Tanah Lempung Lunak. Jurnal Ilmiah Semesta Teknika, 15(1), 90-97.

Yadu, L. \& Tripathi, R.K. (2013). Effect Of The Length Of Geogrid Layers In The Bearing Capacity Ratio Of Geogrid Reinforced Granular Fill-Soft Subgrade Soil System, Procedia - Social and Behavioral Sciences 104, 225-234. 